\title{
An Analysis of Students' Perception of Online Assessments and its Relation to Motivation Towards Mathematics Learning
}

\author{
Ma. Theresa Christine C. Valdez and Lea D. Maderal \\ Mathematics and Statistics Department, De La Salle University-Dasmariñas, Cavite Philippines \\ mcvaldez@dlsud.edu.ph \\ Idmaderal@dlsud.edu.ph
}

\begin{abstract}
Assessing student performance is a challenge faced by most educational institutions during this time when conducting in-campus classes is affected by the pandemic. Use of online assessments to determine student performance is gaining wider acceptance over the traditional paper-and-pen type as it allows evaluation of what the students learned despite the lack of physical classroom interaction. Although there are studies that examine student perceptions about online learning in general, only a few focus on assessments especially those that consider its relation to affective aspects of learning. The views of students being the primary beneficiaries of the technology would give relevant information in designing appropriate online assessments and can bring about the success of its implementation. Thus, this present study investigated the usefulness of online assessments according to the perspective of students particularly in their math subject and its relation to their motivation towards mathematics learning. A mixed methods research design was conducted to determine the perception and motivation of 127 second year level engineering students via a questionnaire survey after exposure to a set of online assessments. Results showed that students have a high level of motivation towards mathematics learning and have positive perception about online assessments. Using factor analysis, variations in the perception were found to be explained by 4 factors focused on ease of use and functionality, personal preference, technical considerations, and complementation with other methods. Some of these factors were found to be significantly related with various aspects of motivation. Interview of students also revealed they found taking online assessments a positive innovation in giving assignments and prefer them over traditional assignments. The findings derived from this study give teachers a basis in designing more effective online assessments particularly those that address the needs of today's generation of learners. Further, for a developing country like the Philippines, findings of this study would greatly contribute to the government and academic sector's efforts in capacity building of its online system of education.
\end{abstract}

Keywords: learning management system, mathematics learning, motivation, online assessment, perception, technology

\section{Introduction}

Technology enhanced learning has been explored and widely practiced in educational institutions across all class levels in many nations. Indeed, it has completely redefined over the years how the teaching-learning process takes place. It is no longer considered as merely a pedagogical supplement but rather as a staple and integral component of the whole educational set-up. Its increase in relevance is highlighted by the fact that there is an educational revolution wherein acquiring $21^{\text {st }}$ century learning skills must be the goal of every academic institution for its students. Durham Public Schools (DPS) characterizes $21^{\text {st }}$ century learners as students who capably utilize technology and digital media to enhance every aspect of their learning (DPS, n.d.). Aristovnik, et al. (2016) describes them as new generations of students who are very familiar and adept with the latest technologies.

Despite the vast impacts of technology in education, particularly in the design and delivery of curriculum, there is still a need to explore new approaches when it comes to assessments (Crisp, Guardia and Hillier, 2016). Assessment is one area in education where technology can be maximally integrated. It is considered as an essential component in education that promotes learning and measures expected outcomes (Clements and Cord, 2013 as cited in Crisp, Guardia and Hillier, 2016). Baneres, et al. (2019) states that one of the great contributions of technology in education is the evolution of assessments into e-assessments. Online assessment or e-assessment includes a broad range of assessment activities such as online essay and computer-marked online examinations (James, 2016). Guardia, Crisp and Alsina (2017) as cited in Baneres (2016) defined them as the use of information and communications technology in facilitating the entire assessment process starting with the creation of assignments up to checking to as far as conducting statistical analysis. Its effectiveness is stressed by Laine, et al. (2016), claiming that online exams are effective for diagnostic, formative, and summative assessments and provide students with the opportunity of demonstrating performance. 
The use of computers in the Philippines' educational set-up has been present for a long time but mostly for aiding instruction only. Internet technology, on the other hand, is being used primarily for engaging students to search for additional learning references. However, their use as means to administer various forms of assessments to students via learning management systems is somewhat limited. Its utilization as such has also been received with mixed views among teachers due to insufficient evidence that it supports both affective and cognitive learning. Sarmiento, Lapinid and Prudente, (2018) stated that there is scarcity in the literature discussing how online assessments affect performance of Filipino students. Likewise, studies investigating how perception of online assessments can be related to other factors that contribute to learning and engagement such as student motivation are quite limited. Adanir, et al. (2020) mentioned that learner's perceptions of online exams have not been widely studied despite its potential to contribute to more effective use of online exams, particularly among developing countries. Their work further emphasized that investigating learners' perceptions on online exams could reveal factors that would make online examinations more accurate and effective.

The Philippines, like most in the world, has been forced to drastically embrace online learning as the new norm, and along with it is the use of online assessments. The current situation brought by the pandemic has given the country's education sector an imperative to make online learning and online assessments successful. However, the country is still in the stage of building its online learning system capability. Various socio-economic factors and lack of existing policies for an online educational system are issues that the government and education sector are trying to resolve so that students across all economic status can cope with the demands of this setup. Joaquin, Biana and Dacela, (2020) suggested that teacher capacity, designing efficient learning environment and looking into the student context are factors that must be considered as the country tries to sustain the learning despite the situation. Hence, this current study would be able to contribute to this need to examine perceptions of students about an integral part of the learning process on giving online assessments. The findings would give academic institutions and educators a basis for designing and administering effective online assessments based on students' perspectives, who are considered as end-users and primary beneficiaries of the technology. Additionally, the study determined if there is a relationship between the perception and the motivation of students towards mathematics learning to give some insights about the affective aspects of learning related to use of online assessments. The following are the research objectives of this study:

1. Determine the perception of the students about online assessments.

2. Identify the opinions of students about online assessments.

3. Identify the factors affecting students' perceptions about online assessments.

4. Determine the motivation level of students towards mathematics learning.

5. Determine the relationship between the perception of the students on online assessments and their motivation level towards mathematics learning.

\section{Literature review}

This section presents related literature to the present study. It is structured presenting four subsections about technology in education and learning management systems, perceptions of online learning, online assessments, and motivation towards mathematics learning.

\subsection{Technology in Education and Learning Management Systems}

The International Bureau of Education (IBE) defines technology-enhanced education as one that utilizes information and communication technologies (ICT) as mediating devices to support student learning through various applications such as web-based learning, computer-based learning and learning management systems (IBE, n.d.). The bureau further emphasized that using appropriate technologies can support the development of innovative teaching practices that enrich learning experiences. One such technology used to deliver classes online is the learning management system.

Learning management systems (LMS) is an internet-based software application used to carry out e-learning courses, with features that permit virtual correspondence between teachers and students (Proprofs Training Maker, n.d.). Academic institutions can choose from a variety of LMS to carry out fully online or blended learning strategies such as WebCT, Moodle, OLAT, and Sakai (Wilson and Randall, 2012 as cited in Papadakis, et al., 2018). Each LMS offers features that can be customized by users depending on their need, capabilities, resources, and infrastructure. To keep up with these technological advancements in education and to meet the changing learning styles of students, many academic institutions in the Philippines are now setting up their own LMS. 
Different components of online learning are gradually being introduced in Philippines schools, mostly at secondary and tertiary levels.

Applying technology in education is seen as an integral component of a teaching-learning environment that addresses the need of $21^{\text {st }}$ century learners. Such students have different learning styles, but they are mostly internet-savvy and uses technology to help them build their knowledge. New technology-driven methods such as flipped classroom, blended learning, massive open online courses (MOOC), and distance learning are deemed the best ways to meet the needs of such learners (Wanner and Palmer, 2015). Such strategies are said to be based on the theory of social learning and constructivism, where students are the active actors in their learning (Young and Jeong, 2020 as cited in Fernandez-Martin, et. al, 2020). Also, these cover three lines of learning namely, individual learning, collaborative learning, and problem-based learning (Vargas and Cordero as cited in Fernandez-Martin, et. al, 2020). Since students assume more active roles in the modern methods of learning, their perception of every aspect of the technology becomes highly relevant as well.

\subsection{Perceptions of Online Learning}

Higher education institutions need to find ways to improve the implementation of technology and LMS so that it would be viewed successfully by all its stakeholders specially the students (Aristovnik, et al., 2016; Papadakis, et.al., 2018). This can be achieved by determining the perception of students about the technology. Student perception consists of the belief and thoughts of students about the technology used in their course. According to Abdullah, Muait and Ganefri (2019), knowing the perception of students is important because this influences their acceptance of the technology. Many research studies discussed that the effectiveness of applying technology in education can be achieved if factors affecting perceptions of students and teachers in its use and their experience in an online learning set-up are examined (Ssekakubo, Suleman and Marsden, 2013; Aristovnik, et al., 2016; Papadakis, et. al, 2018; Kalogiannakis and Papadakis, 2019; Abdullah, Muait and Ganefri, 2019; Moreno-Guerrero, et. al, 2020).

Aristovnik, et al. (2016) presented an analysis of factors influencing the perceived usefulness of e-courses by students at the Faculty of Public Administration, University of Ljubljana. Findings showed that perception of online courses were connected to demographic data and that consistency with face-to-face teaching and teacher feedback significantly influenced student perception while structure and variety of assignments had no significant impact. A similar study was conducted by Papadakis, et al (2018) which investigated how university students perceive the use of learning management systems. Their work examined the perceptions of students at the University of Crete about mobile access to the LMS Moodle. Findings indicate that students did not find Moodle as an effective learning tool because the mobile access provided only a limited usability and reliability. Ssekakubo, Suleman and Marsden (2013) conducted a study that identified the perception of students from University of Cape Town (UCT) and Makerere University on their appropriate LMS access strategies and their most needed LMS services. Results of their survey indicate that the most desired LMS services by the students are assignments, announcements, resources, course outlines and the chat room.

Some research studies focused on determining the factors that influence the intention of teachers to adopt technology in learning. Kalogiannakis and Papadakis (2019) discussed in their work that attitude toward the usefulness of mobile technology in the teaching process strongly influence pre-service teachers' intention to use mobile learning while students' notion of ease of use had an indirect impact. Papadakis (2018) investigated whether gender and age differences influence the acceptance of mobile devices in education. Results revealed that both factors were not significantly correlated with mobile devices acceptance but emphasized the need for teacher training to successfully incorporate mobile technology into pedagogical practice.

All studies mentioned gave indications that knowing perception of users of the technology would give insights on its proper and effective implementation. One aspect of technology integration in learning that must be explored for effective administration is online assessment.

\subsection{Online Assessments}

Assessment is an essential and indispensable component of the teaching-learning process which comes in the form of formative and summative types (Adanir, et al., 2020). Baleni (2015) differentiates the two in terms of objectives where formative aims to improve the teaching and learning while summative focuses on relating gathered data to student performance. 
Like most subjects, math requires constant use of assessments to give both teachers and students basis to know if course learning outcomes are met. It has been a practice in math classes to provide extra activities, or homework to students with the goal of reinforcing what have been learned in class. These homework activities are formative in nature done beyond class hours and allowing students to work independently or with groups of classmates using available and related resources. Rosario, et.al (2015) emphasized the importance of the teacher's role in designing homework activities with a specific purpose and showed that extension homework brought positive impacts on the mathematics achievement of students. However, the benefits of homework were challenged by others stating that the notion that homework teach study skills and promote responsibility does not pass the test of research, logic, and experience (Kohn, 2006 cited in Booth, 2010).

In math, these homework activities typically come in the form of paper-and-pen exercises consisting of problems that were not solved in class. According to Sarmiento (2017), such kind of activities can be time-consuming for teachers to correct and may cause copying work among students. Baleni (2015) stressed the need to explore diverse techniques of assessing learning in an online set-up of classes. Online homework system or online assessments is an emerging technology applied by some teachers complementing the usual paper-and-pen style of giving assessments whereby students may be given unlimited chances of working on a set of problems that vary in every attempt for self-practice. Under this technology, assignments are given and answered by students through the internet. This potentially addresses the issues on pen-and-paper assessments and more importantly, the concern about continuously assessing student performance despite limited or even lack of physical classes.

Several studies support the effective use of online homework in their mathematics classes using different forms of learning management systems. Sarmiento (2017) conducted a study that determined the perception of students of online homework in mathematics of accounting and finance where a set of homework was administered to students using MyOpenMath. Results of this study showed that students found online homework to bring positive impact in their learning. In addition, most students agreed that answering online homework is convenient and that it helped them manage their time. Sarmiento, Lapinid, and Prudente (2018) extended the previous work by determining the effectiveness of online homework in students' performance compared to paper-and-pencil homework. They used a two-group counterbalanced experimental design, where both groups became control and experimental groups and received summative assessments after being subjected to online homework. The results of the summative assessment served as the performance of the participants while their scores in the home-works served as measure of the homework performance. Findings indicated that students performed better than they would by paper-and-pencil.

Adanir, et al. (2020) investigated and compared students' perceptions of online exams at state universities in Turkey and Kyrgyztan via a mixed study research design. Results of the quantitative analysis revealed that Turkish learners found online exams less stressful and more reliable than the traditional mode of taking exams while Kyrgyz learners perceived it otherwise. James (2016) revealed that many students from a regional university in Australia have encountered challenges with having to take major examinations online including technical difficulties and insufficient support. It was also found that ICT infrastructure and reliable connectivity were significant barriers to successful completion of online examinations under secure, proctored conditions. Wanner and Palmer (2015), in their study of flipped courses in a university in Australia, emphasized that attention to assessment practices must be considered to ensure that the learning experience of students is cohesive. Their results further indicated that students preferred blended learning practices over fully online ones stating that they enjoyed clearly structured assessment with wide choices.

Tang and Titus (2002) utilized WebAssign to deliver, collect and grade homework of students in Calculus and General Physics. Students claimed that using the online platform for their homework enhanced their learning of the course content. Most of them preferred WebAssign homework over paper-and-pen homework and the time they spent in engaging with the activities increased significantly. This mode of assessment delivery also promoted cooperative learning and motivated the students to engage and collaborate during activities. Zerr (2007) used Blackboard in administering online homework system, emulating the teacher's presence in the classroom via a sequence of attempt-feedback-reattempt in the assessments. It was found that the participants of the study had a high level of satisfaction in this system. Korkmaz and Karakuz (2009) found that the blended learning model incorporating instruction, homework, individual study, and evaluation contributed more to student attitudes toward geography course when compared to the traditional learning model. 
The mentioned studies give insights as to the how taking online assessments enhances learning and increases students' willingness to engage in activities. Motivation towards the learning process can then be a factor contributing to engagement of students with any type of learning activity, whether in class or online. Majority of Philippines schools relied on the traditional mode of giving assessments and used the online system merely as a supplement pre-pandemic. However, in this "forced" online or remote set-up, assessments remain a vital component of the learning process and thus, the motivation of students to engage on such activities must be considered. Hence, this study investigated this affective aspect and related it with perception of students on online assessments.

\subsection{Motivation Towards Mathematics Learning}

Various studies have emphasized that the affective component of learning and student emotion are as much vital as it is for cognition and that academic success as well as active learning is linked with the affective dimension such as higher degrees of motivation (Booth, 2010; Fared, Jdaitawi and Sheta, 2018; Jeong, Canada and Gomez, 2018, Jdaitawi, M., 2020). Students' attitudes including their motivation play a role on how they involve themselves in the learning process.

Motivation is the reason why one performs a certain activity. In class, students become motivated to engage in learning activities once they perceive its importance and if they can derive benefits from doing such (Pintrich and Schunk, 1996 cited in Tuan, Chin and Shieh, 2005). Tuan, Chin and Shieh (2005) developed a questionnaire that measured the motivation of students towards science learning. In their work, motivation was categorized according to six factors that include self-efficacy, active learning strategies, science learning value, performance goal, achievement goal and learning environment stimulation. Each represents what drives the student to participate in science learning activities. Self-efficacy denoted the belief of students in one's ability to do a task. Active learning strategies focused on the role of students in constructing their own knowledge. Science learning connected motivation to the students' finding relevance of the subject in their daily lives. Performance goal focuses on the desire to out-perform others. Achievement goal was about motivation derived from gaining more competency. Lastly, learning environment stimulation denoted the role of curriculum and set-up in class (Tuan, Chin and Shieh, 2005).

Bhowmik (2014) in his take on constructivism stated that by theory, it is the learner that establishes how he comes to know a concept and that interactive and problem-centered teaching approaches should be considered in mathematics classes. It was also suggested that for student engagement to be established, there should be a broad set of learning activities including those bringing in out-of-school experiences (Denzine and Brown, 2014). These out of school problem-centered activities can materialize in the form of assignments. It may then be logical to consider that to make students engaged in the learning process, they must find motivation towards the process itself. The activities given in and out of class to support learning should then be designed well enough to ensure students perceive their value so that meaningful engagement may be realized.

The studies reviewed provide a framework that serves as a basis for this study where the perception of online assessments can bring about the effective use of technology, and that students' perspectives about the learning process can influence how well motivated they are to take part in the learning activity. Thus, this present study investigates the connection between student perceptions on technology-based and online assessments delivered via learning management systems and their motivation towards math learning.

\section{Methodology}

For the methodology, this paper gives a description of the participants and some demographic profile, particularly their gender, and degree program in the university. Next, the research design is discussed followed by the development of the questionnaires used in the study and how the data were analyzed. Lastly, the research procedure was outlined.

\subsection{Participants of the Study}

The participants of the study were second year engineering students from a university in Cavite, Philippines who were chosen via a convenience sampling method. Out of the 432 engineering students enrolled during the semester and taking integral calculus, only 127 (29.4\%) belonging to 5 intact sections were selected as they were the only ones to complete all the online assessments and answer the survey questionnaires. These students have been previously exposed to the learning management system of the university during their first year in 
college and were already familiar with its features including online assessment. Tables 1 and 2 show the demographic profile of the participants in terms of gender (32.3\% female and $67.7 \%$ male participants) and degree program in the university. The degree programs of the students were civil engineering (CEE, 39.4\%), computer engineering (CPE, 20.5\%), electronics engineering (ECE, 19.7\%) and mechanical engineering (MEE, $20.5 \%)$.

Table 1: Frequency distribution of students according to gender

\begin{tabular}{lrrrr}
\hline \multicolumn{5}{c}{ Gender } \\
\hline & & & \multicolumn{2}{c}{ Cumulative } \\
& Frequency & Percent & Valid Percent & Percent \\
\hline FEMALE & 41 & 32.3 & 32.3 & 32.3 \\
MALE & 86 & 67.7 & 67.7 & 100.0 \\
\hline Total & 127 & 100.0 & 100.0 & \\
\hline
\end{tabular}

Table 2: Frequency distribution of students according to degree program

\begin{tabular}{rrrrrr}
\hline \multicolumn{5}{c}{ Degree Program } \\
\hline \multirow{6}{*}{ Valid } & CEE & Frequency & Percent & Valid Percent & Cumulative \\
& Percent \\
& CPE & 26 & 39.4 & 39.4 & 39.4 \\
& ECE & 20.5 & 20.5 & 59.8 \\
& MEE & 25 & 19.7 & 19.7 & 79.5 \\
& Total & 127 & 20.5 & 20.5 & 100.0 \\
\hline
\end{tabular}

\subsection{Research Design}

A mixed methods research design was utilized where a combination of qualitative and quantitative data is obtained and analyzed to provide answers to the problems in this study. The qualitative data obtained were the opinion of the students about taking online homework or assessments. The quantitative data consisted of the level of motivation towards mathematics learning and perception on online assessments of students obtained via the 4-point scale opinion questionnaire surveys.

\subsection{Instrument and Statistical Analysis}

The instrument used to measure the motivation towards math learning (MTML) was based on the Students' Motivation towards Science Learning (SMTSL) questionnaire developed by Tuan, Chin and Shieh (2005). The researchers asked for the approval of the developer of the questionnaire to allow them to utilize the material but with some modifications to meet the objective of measuring the motivation towards mathematics learning of the students. The modification involved changing the context of the questionnaire from science to mathematics learning. Some negatively stated items from the original were also reversed as per suggestion by the evaluators consulted by the researchers during content validation. Some of the changes adapted by the researchers included the following: "Whether the science content is difficult or easy, I am sure that I can understand it" was changed to "Whether the math content is difficult or easy, I am sure I can understand it"; and "I am willing to participate in this science course because the teacher uses a variety of teaching methods" was changed to "I am willing to participate in this math course because the teacher uses a variety of teaching methods". The rest of the items in the SMTSL questionnaire were changed in a similar manner.

The instrument to measure the perception on online homework was based on the material used by Sarmiento (2017). A few items in the questionnaire were reworded to indicate that the perception was directed towards the students' online homework in calculus. The 24-item questionnaire included 21 items that measure the perception score and 3 items that determined if the students utilized their unlimited attempts to answer each online homework to prepare for summative exams, the techniques they used to solve the given problems and if they found the online assessments useful.

The students responded by rating each item in the questionnaires using the 4-point scale: 1-strongly disagree, 2 - disagree, 3-agree, and 4-strongly agree. Initially, the questionnaire was designed to use a 5-point scale but based on the comments of the evaluators of the questionnaire, it was suggested to exclude the neutral option to get a clearer inference on the inclination of the students in terms of their motivation towards math and their perception on online assessments. Also, following the work of Sarmiento (2017), the researchers opted to use only a 4-point scale in both questionnaires, whereby the "neutral" or "no opinion" option was not included to 
ensure that the respondents would specify their level of agreement on each of the propositions in the questionnaires. Using an even number of options is said to eliminate the middle choice which gives respondents a means not to show their actual preference and thus providing researchers with little useful data (University at Buffalo, 2019). Table 3 shows the interpretation of the results obtained from the instrument for measuring the motivation towards math of the students and perception.

Table 3: Interpretation of student responses for motivation and perception instrument

\begin{tabular}{cccc}
\hline Rating & Verbal Interpretation & Level of Motivation & Level of Perception \\
\hline $1.00-1.49$ & Strongly disagree & Very low motivation & Highly Negative \\
$1.50-2.49$ & Disagree & Low motivation & Negative \\
$2.50-3.49$ & Agree & High motivation & Positive \\
$3.50-4.00$ & Strongly agree & Very high motivation & Highly Positive \\
\hline
\end{tabular}

A reliability analysis using 30 samples was used to verify the consistency of the instrument where a Cronbach's Alpha of 0.927 was obtained indicating reliability of the test. Factor analysis was used to identify the factors or components that possibly caused the variation on the students' perception of online learning. A Kaiser-MayerOlkin Measure of Sampling Adequacy (KMO) test was conducted to determine if the sample is adequate to perform factor analysis. A KMO value of 0.893 and $p$-value of 0.000 were obtained indicating adequacy. Lastly, a multiple correlation analysis via the Pearson $r$ Correlation Coefficient was applied to determine if there were significant relationships between the factors extracted from the students' perception survey and the factors that constitute the students' motivation towards math.

\subsection{Research Procedure}

Initially, the researchers prepared the online assessments and ensured that the level of difficulty of the items were similar. These items were taken from previous assessments made by the researchers during their traditional pen-and-paper assessments in the previous school years. A total of 4 online assessments were prepared for this study one each for the sub-topics of techniques of integration, namely: integration by parts, trigonometric integrals, trigonometric substitution, and partial fraction decomposition. These assessments were all multiple-choice type of assessment involving different problems that students needed to answer online via the LMS of the university. Each online assessment was due for a week, with students given an unlimited number of attempts and their best scores among attempts were given credit. Students may get a different set of 10 questions in each attempt. The students got to see their scores right after submission and they were provided with a summary of what items they answered incorrectly. The students were given opportunities to submit clarifications about the homework via the chat and forum feature of the LMS for immediate feedback. Once all the assessments were completed, the students answered the instruments for perception and motivation through the LMS.

\section{Results}

The results of the survey and statistical analysis are presented in the following sequence: perception of students, factors affecting students' perception obtained using factor analysis, motivation level of students and correlation analysis.

\subsection{Students' Perception of Online Assessments}

Table 4 shows the mean responses on each item in the students' perception questionnaire. Generally, the students claimed they had a positive experience taking online assessments. They strongly agreed that this kind of assessment should be done not just in calculus but also in other math courses. Among the items in the perception survey, the item "Doing online homework helps me practice answering exercises in Calculus" had the highest mean of 3.65, followed by "Getting immediate result and feedback from online homework motivates $m e$ " with a mean of 3.62 and the third highest is "I like doing online homework" with a mean of 3.57. Based on standard deviation, these three items were among the 5 having lowest variation on the responses of the students indicating that they are mostly in agreement with the use of the online assessments in helping them prepare for their subject, the immediate feedback function gives them motivation and that they generally like doing online homework. 
Table 4: Students' perception of online homework in integral calculus

\begin{tabular}{|c|c|c|c|}
\hline & Perception of Online Homework & Mean & $\begin{array}{c}\text { Std. } \\
\text { Deviation }\end{array}$ \\
\hline P1 & I like doing online homework. & 3.5748 & .62386 \\
\hline P2 & $\begin{array}{l}\text { Doing online homework is a positive } \\
\text { innovation to the way homework is } \\
\text { administered. }\end{array}$ & 3.4803 & .67671 \\
\hline P3 & $\begin{array}{l}\text { Online homework has to be spread out to } \\
\text { other math courses besides Calculus. }\end{array}$ & 3.4961 & .74401 \\
\hline P4 & $\begin{array}{l}\text { Doing online homework has disadvantages for } \\
\text { me.* }\end{array}$ & 2.6929 & .98005 \\
\hline P5 & $\begin{array}{l}\text { I prefer paper-and-pencil homework to online } \\
\text { homework in Calculus.* }\end{array}$ & 2.5906 & .97878 \\
\hline P6 & $\begin{array}{l}\text { Technical computer problems reduce my } \\
\text { online homework grade.* }\end{array}$ & 2.5039 & .96670 \\
\hline P7 & $\begin{array}{l}\text { Online homework helps me manage my time } \\
\text { in answering homework. }\end{array}$ & 3.3150 & .74216 \\
\hline P8 & $\begin{array}{l}\text { Getting immediate result and feedback from } \\
\text { online homework motivates me. }\end{array}$ & 3.6220 & .58998 \\
\hline P9 & $\begin{array}{l}\text { Doing online homework helps improve my } \\
\text { performance in my Calculus class. }\end{array}$ & 3.4409 & .69754 \\
\hline P10 & $\begin{array}{l}\text { Along with online homework, paper-and- } \\
\text { pencil homework should also be given to } \\
\text { students. }\end{array}$ & 3.2520 & .80641 \\
\hline P11 & Answering online homework scares me.* & 3.1575 & .83023 \\
\hline P12 & I want to continue doing online homework. & 3.4488 & .67505 \\
\hline P13 & $\begin{array}{l}\text { I am more comfortable doing homework } \\
\text { online compared to paper-and-pencil. }\end{array}$ & 3.1181 & .80291 \\
\hline P14 & $\begin{array}{l}\text { I encountered difficulties accessing the online } \\
\text { homework.* }\end{array}$ & 2.8425 & .95473 \\
\hline P15 & $\begin{array}{l}\text { The online homework environment is } \\
\text { appropriate and convenient for users. }\end{array}$ & 3.3858 & .63054 \\
\hline P16 & $\begin{array}{l}\text { Doing online homework is a positive } \\
\text { experience. }\end{array}$ & 3.5039 & .58924 \\
\hline P17 & $\begin{array}{l}\text { Doing online homework helps me practice } \\
\text { answering exercises in Calculus. }\end{array}$ & 3.6535 & .56874 \\
\hline P18 & $\begin{array}{l}\text { The online homework platform is easy to use } \\
\text { and is user friendly. }\end{array}$ & 3.4724 & .66460 \\
\hline P19 & I do not want to take any online homework.* & 3.4961 & .73327 \\
\hline P20 & $\begin{array}{l}\text { Online homework does not help me prepare } \\
\text { for quizzes and examinations.* }\end{array}$ & 3.4803 & .77511 \\
\hline P21 & $\begin{array}{l}\text { Online homework increases the amount of } \\
\text { time I spent studying. }\end{array}$ & 3.2677 & .81112 \\
\hline
\end{tabular}

\subsection{Opinion of Students about Taking Online Assessments}

The opinion of students about taking online assessments were obtained via open-ended questions in the perception survey. There were 72 students (56.7\%) who preferred taking online assessments compared to the paper-and-pen form. There were $116(91.3 \%)$ students who responded that taking the online assessment helped them prepare for their major exam in calculus. The instrument also identified how the students answered their online assessments. There were 15 (11.8\%) who said that they solved the problems independently by referring to their lecture notes, $3(2.4 \%)$ responded that they solved using only sources from the internet or math softwares while the majority (109-85.8\%) utilized various sources including their notes, internet available references and math softwares. They also collaborated with their classmates via group studies.

\subsection{Factors Affecting the Students' Perception of Online Assessments}

Factor analysis was conducted to understand what aspects of perception on online assessments mostly explains the variation in the responses of students. Based on the Scree plot generated in the analysis, 4 factors or components were extracted from the set of 21 questions on perception. The eigenvalue greater than 1 was considered to decide on the number of factors. This is shown in Figure 1. 


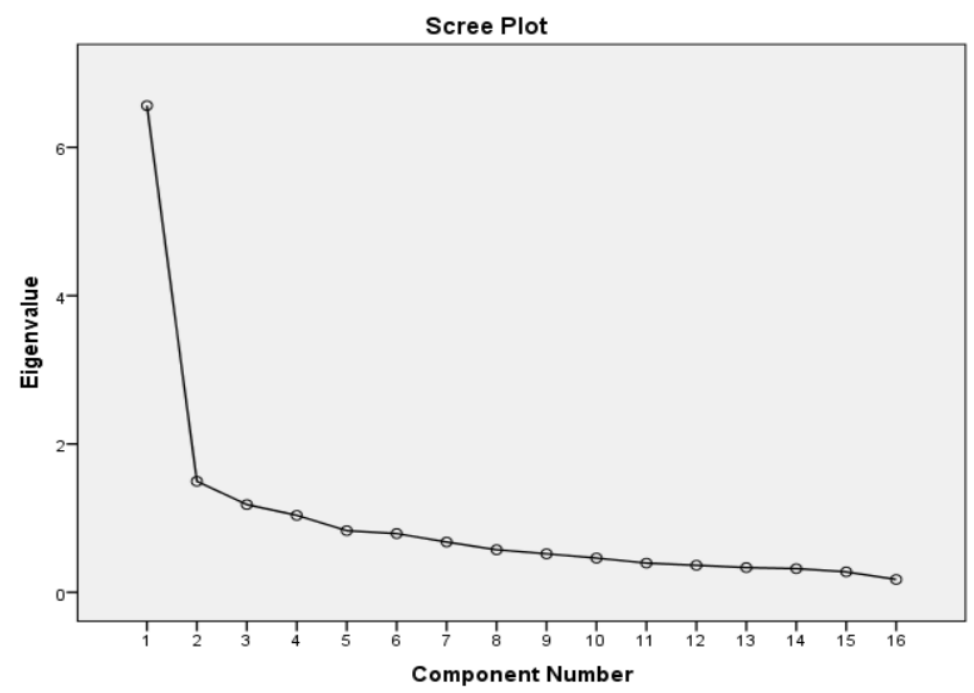

Figure 1: Scree plot on the factor analysis of the students' perception of online homework

Table 5 shows the summary of the results of the factor analysis where $64.255 \%$ of the variation of students' perception can be explained by the 4 factors or components extracted from the data. The remaining $35.745 \%$ was not captured. Based on the analysis, Factor 1 explains the largest variation on the students' perception, with a variance of $41.015 \%$.

Table 5: Factor analysis results

\begin{tabular}{|c|c|c|c|c|c|c|c|c|c|}
\hline \multicolumn{10}{|c|}{ Total Variance Explained } \\
\hline \multirow{2}{*}{ Component } & \multicolumn{3}{|c|}{ Initial Eigenvalues } & \multicolumn{3}{|c|}{$\begin{array}{c}\text { Extraction Sums of Squared } \\
\text { Loadings }\end{array}$} & \multicolumn{3}{|c|}{$\begin{array}{c}\text { Rotation Sums of Squared } \\
\text { Loadings }\end{array}$} \\
\hline & Total & $\begin{array}{c}\% \text { of } \\
\text { Variance }\end{array}$ & $\begin{array}{c}\text { Cumulative } \\
\%\end{array}$ & Total & $\begin{array}{c}\% \text { of } \\
\text { Variance }\end{array}$ & $\begin{array}{c}\text { Cumulative } \\
\%\end{array}$ & Total & $\begin{array}{c}\% \text { of } \\
\text { Variance }\end{array}$ & $\begin{array}{c}\text { Cumulative } \\
\%\end{array}$ \\
\hline 1 & 6.562 & 41.015 & 41.015 & 6.562 & 41.015 & 41.015 & 5.428 & 33.925 & 33.925 \\
\hline 2 & 1.497 & 9.357 & 50.372 & 1.497 & 9.357 & 50.372 & 1.892 & 11.825 & 45.75 \\
\hline 3 & 1.183 & 7.396 & 57.768 & 1.183 & 7.396 & 57.768 & 1.581 & 9.882 & 55.632 \\
\hline 4 & 1.038 & 6.487 & 64.255 & 1.038 & 6.487 & 64.255 & 1.38 & 8.623 & 64.255 \\
\hline
\end{tabular}

Extraction Method: Principal Component Analysis.

Table 6 enumerates the items in the questionnaire on students' perception that are closely related and are clustered as one component or one factor that explains the variation in the results. Analysis revealed that only 16 items were left because some of the items are highly correlated to factor 1 . Referring to the actual items in Table 4, we find that P3, P7, P8, P9, P12, P15, P16, P17, P18 and P21 are highly correlated thus are clustered as factor 1. P19 and P20 are clustered as factor 2, P6 and P14 are clustered as factor 3 , and P5 and P10 are clustered as factor 4.

Table 6: Component matrix of the students' perception of online homework

\begin{tabular}{|c|c|c|c|c|}
\hline \multicolumn{5}{|c|}{ Rotated Component Matrix ${ }^{a}$} \\
\hline & \multicolumn{4}{|c|}{ Component } \\
\hline & 1 & 2 & 3 & 4 \\
\hline P3 & 0.728 & & & \\
\hline P5 & & & & 0.592 \\
\hline P6 & & & 0.721 & \\
\hline P7 & 0.675 & & & \\
\hline P8 & 0.8 & & & \\
\hline P9 & 0.693 & & & \\
\hline P10 & & & & -0.801 \\
\hline P12 & 0.586 & & & \\
\hline P14 & & & 0.744 & \\
\hline P15 & 0.784 & & & \\
\hline P16 & 0.865 & & & \\
\hline P17 & 0.716 & & & \\
\hline P18 & 0.721 & & & \\
\hline
\end{tabular}




\begin{tabular}{lllll}
\hline \multicolumn{5}{c}{ Rotated Component Matrix ${ }^{\text {a }}$} \\
\hline \multicolumn{4}{c}{ Component } \\
& 1 & 2 & 3 & 4 \\
\hline P19 & \multicolumn{3}{c}{0.754} \\
P20 & & 0.86 & \\
P21 & 0.583 & & \\
\hline
\end{tabular}

Extraction Method: Principal Component Analysis.

Rotation Method: Varimax with Kaiser Normalization.

a. Rotation converged in 6 iterations.

Descriptive information shown in Table 7 about the items shows that factors 1, 2, 3 and 4 have means of 3.4628, $3.4882,2.6732$ and 2.9213 . This gives an over-all perception mean of 3.2982 which is interpreted as positive perception on online assessments.

Table 7: Descriptive statistics of the factors extracted

\begin{tabular}{lrr} 
Item & Mean & Std. Deviation \\
\hline P3 & 3.4961 & 0.74401 \\
P7 & 3.315 & 0.74216 \\
P8 & 3.622 & 0.58998 \\
P9 & 3.4409 & 0.69754 \\
P12 & 3.4488 & 0.67505 \\
P15 & 3.3858 & 0.63054 \\
P16 & 3.5039 & 0.58924 \\
P17 & 3.6535 & 0.56874 \\
P18 & 3.4724 & 0.6646 \\
P21 & 3.2677 & 0.81112 \\
\hline Factor1 & $\mathbf{3 . 4 6 2 8}$ & $\mathbf{0 . 5 0 0 5 9}$ \\
\hline P19 & 3.4961 & 0.73327 \\
P20 & 3.4803 & 0.77511 \\
\hline Factor2 & $\mathbf{3 . 4 8 8 2}$ & $\mathbf{0 . 6 7 1 0 1}$ \\
\hline P6 & 2.5039 & 0.9667 \\
P14 & 2.8425 & 0.95473 \\
\hline Factor3 & $\mathbf{2 . 6 7 3 2}$ & $\mathbf{0 . 7 5 6 9 2}$ \\
\hline P5 & 2.5906 & 0.97878 \\
P10 & 3.252 & 0.80641 \\
\hline Factor4 & $\mathbf{2 . 9 2 1 3}$ & $\mathbf{0 . 5 5 0 7}$ \\
\hline Overall & $\mathbf{3 . 2 9 8 2}$ & $\mathbf{0 . 4 3 2 6 7}$ \\
Perception & & \\
\hline
\end{tabular}

The four factors were identified as ease of use and functionality, personal preference, technical considerations, and complementation with other methods. The items P3, P7, P8, P9, P12, P15, P16, P17, P18 and P21 found to be highly correlated and clustered as factor 1 , all focus on the ease of use of the technology. These pertained to items were the respondents agreed that the delivery of online assessment was user-friendly, convenient and gave them a positive experience. Likewise, the items targeted functionality of the online assessments, where students agreed that it helped them study in their subject, gave their needed results and feedback, and contributes to improving their performance in class. Factor 2 is explained by the items P19 and P20, which focuses more on the personal preference of students on the type of activity, whether online or not, they want to experience in class. Items P6 and P14 are clustered as factor 3, which focused on technical considerations such as difficulties encountered while doing their online assessments. Finally, P5 and P10 are clustered as factor 4 where the responses of student focused on complementing online and paper-and-pen type of assessments in their classes.

\subsection{Motivation of Students towards Math Learning}

The motivation level of the engineering students was determined after their exposure to the online assessments in Calculus. The motivation level was categorized according to 6 factors, namely self-efficacy, active learning strategies, math learning value, performance goal, achievement goal and learning environment stimulation. Table 8 summarizes the results obtained from the questionnaire. 
Table 8: Motivation levels of students towards math learning

\begin{tabular}{lccc}
\hline Motivation Factors & Mean & Std. Deviation & Interpretation \\
\hline Self-Efficacy & 3.15 & .422 & High level of motivation \\
Active Learning Strategies & 3.46 & .380 & High level of motivation \\
Math Learning Value & 3.50 & .418 & Very high level of motivation \\
Performance Goal & 3.16 & .447 & High level of motivation \\
Achievement Goal & 3.48 & .455 & High level of motivation \\
Learning Environment & 3.32 & .447 & High level of motivation \\
Stimulation & 3.35 & 0.279 & High level of motivation \\
\hline Over-all Motivation & & &
\end{tabular}

Self-efficacy accounted for the confidence of students in dealing with math concepts in their class. This measured the students feeling of self-sufficiency and belief in themselves to perform well in the subject as well as solving difficult math problems. Results in Table 8 show that the students have high level of self-efficacy with over-all mean rating of 3.15 implying that students strongly believed in their capacity to do well in math. The next factor is active learning strategies which measured the students' motivation to engage in activities particularly when presented with new math concepts. This determined if students connected their past learnings with the new concepts and if they find reasons for their mistakes. The motivation of the students based on this factor is 3.46 , implying that students still engage in math activities even if they commit mistakes and find concepts difficult to understand. Math learning value focused on motivation emerging from knowing the importance of math. Table 8 reflects a mean rating of 3.50 which implies that students believed that math is useful in their daily life and in their field of study. The fourth factor measures motivation arising from students desire to out-perform others. Results showed that the mean performance goal is 3.16 which indicates that students get motivated by getting good grades. Achievement goal denotes motivation derived from seeing progress in their math performance.

The mean achievement goal rating is 3.48 which meant that students were highly motivated when they see better performance and when they can solve more difficult math problems. Lastly, learning environment stimulation showed a mean rating of 3.32. This indicated that students are motivated by the set-up of their class such as having enough class interaction and experiencing different teaching strategies that pose challenges to them. The students agreed that the set-up of class as well as dynamic and new activities make them more willing to participate in class. The over-all motivation of the students towards math learning is 3.35 which indicates that students have high level of motivation.

\subsection{Relation between the Students' Perception of Online Homework and Motivation towards Math Learning}

Multiple correlation analysis was done to determine the relationship of the factors arising from the perception of students on online assessments with the motivation level of students. Further, it was determined to which aspects of motivation are the factors significantly correlated to. As reflected in Table 9, factor 1 was found to be correlated to the motivation aspects of active learning strategies ( $r=0.247)$, math learning value $(r=0.281)$, and learning environment stimulation $(r=0.314)$ at 0.05 level of significance. The $p$-values corresponding to these are all less than 0.01 indicating high level of statistical significance of results obtained. Factor 2 was found to have significant correlation with self-efficacy $(r=0.205, p=0.021)$ and active learning strategies $(r=0.206, p=0.02)$ at 0.01 level of significance and have high significant correlation with math learning value $(r=0.236, p=0.007)$ at 0.05 level of significance. Factor 3 was found to have high level of significance with self-efficacy $(r=0.265$, $p=0.003)$ at 0.05 level of significance while it is significantly correlated with active learning strategies $(r=0.204$, $p=0.022$ ) at 0.05 level of significance. Finally, factor 4 was found to be significantly correlated with active learning strategies $(r=0.208, p=0.019)$ as well as math learning value $(r=0.206, p=0.02)$ at 0.05 level of significance.

The over-all students' perception of online assessments has a highly significant correlation with the over-all motivation level $(r=0.388, p=0)$. These observations indicate that as the perception scores of students on online assessments increase, the level of motivation also increases and vice versa. This could be an indication that perception influences motivation or motivation influences perception in the same direction. 
Table 9: Correlation analysis between students' perception and motivation towards math learning

\begin{tabular}{|c|c|c|c|c|c|c|c|}
\hline \multicolumn{8}{|c|}{ Correlations } \\
\hline \multicolumn{2}{|c|}{$\begin{array}{l}\text { Factors derived from the } \\
\text { Perception of Students on } \\
\text { Online Assessment }\end{array}$} & $\begin{array}{l}\text { Self- } \\
\text { efficacy }\end{array}$ & $\begin{array}{c}\text { Active } \\
\text { Learning } \\
\text { Strategies } \\
\end{array}$ & $\begin{array}{l}\text { Performance } \\
\text { Goals }\end{array}$ & $\begin{array}{l}\text { Math } \\
\text { Learning } \\
\text { Value } \\
\end{array}$ & $\begin{array}{c}\text { Learning } \\
\text { Environment } \\
\text { Stimulation } \\
\end{array}$ & $\begin{array}{c}\text { Ovel-all } \\
\text { Motivation }\end{array}$ \\
\hline \multirow{3}{*}{ Factor1 } & $\begin{array}{l}\text { Pearson } \\
\text { Correlation }\end{array}$ & 0.133 & $.247^{* *}$ & -0.067 & $.281^{* *}$ & $.314^{* *}$ & $.324^{* *}$ \\
\hline & $\begin{array}{l}\text { Sig. (2- } \\
\text { tailed) }\end{array}$ & 0.135 & 0.005 & 0.453 & 0.001 & 0 & 0 \\
\hline & $\mathrm{N}$ & 127 & 127 & 127 & 127 & 127 & 127 \\
\hline \multirow{3}{*}{ Factor2 } & $\begin{array}{l}\text { Pearson } \\
\text { Correlation }\end{array}$ & $.205^{*}$ & $.206^{*}$ & 0.158 & $.236^{* *}$ & 0.123 & $.276^{* *}$ \\
\hline & $\begin{array}{l}\text { Sig. (2- } \\
\text { tailed) }\end{array}$ & 0.021 & 0.02 & 0.076 & 0.007 & 0.169 & 0.002 \\
\hline & $\mathrm{N}$ & 127 & 127 & 127 & 127 & 127 & 127 \\
\hline \multirow{3}{*}{ Factor3 } & $\begin{array}{l}\text { Pearson } \\
\text { Correlation }\end{array}$ & $.265^{* *}$ & $.204^{*}$ & 0.097 & 0.15 & 0.084 & $.265^{* *}$ \\
\hline & $\begin{array}{l}\text { Sig. (2- } \\
\text { tailed) }\end{array}$ & 0.003 & 0.022 & 0.276 & 0.092 & 0.35 & 0.003 \\
\hline & $\mathrm{N}$ & 127 & 127 & 127 & 127 & 127 & 127 \\
\hline \multirow{3}{*}{ Factor4 } & $\begin{array}{l}\text { Pearson } \\
\text { Correlation }\end{array}$ & 0.157 & $.208^{*}$ & -0.139 & $.206^{*}$ & $.197^{*}$ & $.244^{* *}$ \\
\hline & $\begin{array}{l}\text { Sig. (2- } \\
\text { tailed) }\end{array}$ & 0.077 & 0.019 & 0.12 & 0.02 & 0.027 & 0.006 \\
\hline & $\mathrm{N}$ & 127 & 127 & 127 & 127 & 127 & 127 \\
\hline \multirow{3}{*}{$\begin{array}{l}\text { Over-all } \\
\text { Perception }\end{array}$} & $\begin{array}{l}\text { Pearson } \\
\text { Correlation }\end{array}$ & $.218^{*}$ & $.300^{* *}$ & -0.019 & $.309^{* *}$ & $.308^{* *}$ & $.388^{* *}$ \\
\hline & $\begin{array}{l}\text { Sig. (2- } \\
\text { tailed) }\end{array}$ & 0.014 & 0.001 & 0.832 & 0 & 0 & 0 \\
\hline & $\mathrm{N}$ & 127 & 127 & 127 & 127 & 127 & 127 \\
\hline
\end{tabular}

**. Correlation is significant at the 0.01 level (2-tailed).

*. Correlation is significant at the 0.05 level (2-tailed).

\section{Discussion and conclusion}

The discussion of the results along with their implications are presented such that the discussion for problems 1 and 2 are given together, followed by the discussion for problem 3 and lastly, the discussion of problems 4 and 5 are given together.

1.1.5 Research Problems: (1) Determine the perception of the students about online assessments and (2) Identify the opinions of students about online assessments.

Results of the study showed that students have a positive perception on the use of online assessments. They agreed that the integration of technology in the way they take their assessments is a good innovation that allows them to get immediate feedback and results in their assessments. Also, majority of the students utilized the online assessments to prepare for their exam. They find that having unlimited attempts to take the online assessments exposes them to different types of problems useful for practice in problem-solving. The findings of this study are in line with the results of Adanir, et al. (2020) which mentioned that Kyrgyz students find the potential of online exams to improve learning through the provision of immediate feedback. This is further supported by the works of Sarmiento (2017) and Baleni (2015) where both studies emphasized that doing online assessments gave students opportunities to view their results and use the feedback to study further as final preparations for their summative tests.

In this study, the students also found that the use of online assessments provided them new and a variety in the teaching-learning strategies done in class. The results adhere to the suggestion by Lawson and Lawson to provide students with a broad set of activities (Lawson and Lawson, cited in Denzine and Brown, 2014) and by the results of Wanner and Palmer (2015) stating that students enjoyed the wider choices in learning and assessment they experienced in flipped classroom. 


\subsubsection{Research Problem (3) Identify the factors affecting students' perceptions about online assessments}

Based on the factor analysis conducted, there are 4 factors that explains the variation on the perception of students on online assessments. The perception of students is generally explained by the first factor, ease of use and functionality, which explained $41.015 \%$ of the variation in the responses of students. This implied that the perception of students is focused on the convenience in the use of technology and if they find that it serves its purpose. Students tend to become more accepting of a new strategy or technology if they feel that it helps them achieve their learning goals. The online assessments were meant primarily to provide additional exercises for students thus they find that doing multiple attempts serve the purpose of helping them practice and learn more. This is supported by the work of Kalogiannakis and Papadakis (2019) whose results ranked usefulness of mobile learning in the teaching process strongly influenced the attitude of pre-service teachers in adopting a certain technology followed by ease of use. The work of Sarmiento (2017) also backs up the results of the study pointing out that students found taking online exams convenient because it can be accessed anytime within the allotted period.

The other factors derived from this present study are personal preference (9.357\%), technical considerations (7.396\%) and complementation with other methods (6.487\%). The students found that online assessments can be an effective complement to doing paper-and -pen assessments and that most prefer it over the use of purely traditional means. This is supported by the work of Laine, et. al (2016) who despite giving positive feedback about taking electronic examinations also mentioned that pen-and-paper assessment is still an essential component for math assessments that can work together with the electronic exam. The technical difficulties are emphasized in the work of James (2016) where many students shared that their challenges in taking online examinations are due to technical difficulties, ICT infrastructure and internet connectivity. Reliable internet connection and lack of efficient gadgets that support online activities are common concerns among Filipino students. Thus, technical difficulties often arise and is a major issue that must be taken into consideration by academic institutions so that the learning experience remain positive for all students.

1.3.5 Research Problems (4) Determine the motivation level of students towards mathematics learning and (5) Determine the relationship between the perception of the students on online assessments and their motivation level towards mathematics learning.

The motivation level of students towards mathematics learning was found to be of high level, with a mean of 3.35. This motivation level is explained by 6 factors namely self-efficacy, active learning strategies, math learning value, performance goal, achievement goal, and learning environment stimulation. Multiple correlation analysis revealed that perception on online assessments is significantly correlated to motivation, on all its aspects except performance goals. This is in line with the results of the study of Abdullah, Muait and Ganefri (2019) where use of technology as part of teaching tools was shown to influence student motivation for the enhancement of student's overall learning experience. It is important to note that the high level of motivation of students after the exposure to online assessments maybe attributed to the type of student participants in the study. Since the students are enrolled in engineering programs, they have many subjects in mathematics in their curriculum or those subjects applying mathematics principles. This explains why the students acknowledge that math is important to their field of study and that they want challenging math problems so they can improve their understanding and knowledge of the subject. However, they are also dynamic students who require variety in their classes and tend to be competitive as well. Hence, the use of online assessments where they can answer different sets of problems in every attempt engages them more. They want to be exposed to different problems so that they can practice solving and they are encouraged to get better results in every attempt that they take. This is supported by the findings of Korkmaz and Karakuz (2009) where in Geography courses, the use of blended learning model contributed positively to students' attitudes towards their course.

The results of this present study support the effectiveness of online homework and the positive reception of students on this kind of assessment strategy. Like the results of Tang and Titus (2002), Zerr (2007) and Sarmiento (2017), the participants in this study also generally preferred online homework system over paper assignments, even though all research studies utilized different platforms for administering the online assessment. The participants became more motivated as reflected in their agreement that online homework increased their amount of time spent in studying and that most of them collaborated with their classmates in working on the different assessments. This coincides with the results of Tang and Titus (2002) where in their study, a significant increase in time of engagement was found. In the work of Sarmiento (2017), perception on online homework for her students in mathematics of accounting and finance was also of high level like the results of this paper. 
This study also reflected what was found in her research and that is for students, taking online homework had a positive impact on learning.

This paper was able to highlight the key aspects needed in the effective use of online assessments and was able to show how it can influence the motivation level of students toward mathematics learning. In conclusion, knowing the perception on online assessments can give educators insights as to how to carry out the technology in the most effective way. This study emphasizes that design should focus on functionality, wherein the online assessments must provide opportunities for students to practice and prepare for their summative or major exams. The variety in problems and the multiple attempts can help address this aspect. It should also focus on ease of use with clear structure and guidelines. A well-designed online assessment can influence the motivation level of students and increase their engagement in class. Over-all, the use of online homework is a welcome addition to the different strategies that teachers employ to encourage active engagement among students. The benefits including ease of task of grading student works and being able to provide them with varied activities for practice and self-learning far outweigh the somewhat meticulous stage of preparing relevant materials.

\section{Recommendation and limitations}

This study was limited to the experience of students in their math subject during the semester. Hence the perception was directed only towards perception on online assessments within the context of their mathematics class. Likewise, this study did not investigate effectiveness of the online assessment on improving the motivation of students to engage more in their mathematics classes but focused on their correlation only.

The main challenges encountered by the researchers were the limited means to verify whether the students answered the assessments without resorting to guessing because the assessments were of multiple-choice type and the likelihood that the students utilized softwares to solve the problems instead of solving them. The researchers tried to discuss some problems from the online assessment during the face-to-face meeting asking students to explain their solution to determine if they knew the solution to the problems. The students were reminded that during their major exam, the questions will be based from the online assessments, but their solutions will be required for submission. This way they are encouraged to work on the solutions to the problems they encountered.

Considering the current situation in most countries, the use of online assessments in evaluating students and enhancing the learning process is now a requirement. Academic institutions in the Philippines must double their efforts in setting up infrastructure and learning management systems, formulating policies, and training teachers in the use of ICT and designing online materials including online assessments. Hence, studies that focus on how it can be carried effectively and accurately must be done. Future research can explore best practices in the delivery of online assessment to maximize its utility and benefits. It is also recommended to study its impact on student performance and come up with structural models that identifies what other factors contribute to acceptance of both teachers and students of online assessments.

\section{References}

Abdullah, R., Muait, J., and Ganefri. 2019. Students' perception towards modern technology as teaching aids. Asian Journal of Assessment in Teaching and Learning. 9(2), pp. 37-42. DOI:10.37134/ajatel.vol9.no2.5.2019

Adanır, G., İsmailova, R., Omuraliev, A. and Muhametjanova, G., 2020. Learners' perceptions of online exams: a comparative study in Turkey and Kyrgyzstan. International Review of Research in Open and Distributed Learning [online] Available at: < http://www.irrodl.org/index.php/irrodl/article/view/4679/5331> [Accessed 10 April 2021].

Aristovnik, A., Keržič, D., Tomaževič, N. and Umek, L., 2016. Determining factors of students' perceived usefulness of elearning in higher education. Paper presented at the International Association for Development of the Information Society (IADIS) International Conference on e-Learning, Madeira, Portugal, Jul 1-4, 2016, Part I, pp. 3-10. .Available at: https://eric.ed.gov/?id=ED571462 [Accessed 11September 2021]

Baleni, Z. 2015. Online formative assessment in higher education: its pros and cons. The Electronic Journal of e-Learning, 13(4), pp. 228-236.https://academic-publishing.org/index.php/ejel/article/view/1730 [Accessed 11 September, 2021]

Baneres, D., Whitelock, D., Ras, E., Karadeniz, A., Guerrero-Roldan, E., and Rodriguez, M., 2019. Technology enhanced learning or learning driven by technology. International Journal of Educational Technology in Higher Education, Available at: $<$ https://educationaltechnologyjournal.springeropen.com/articles/collections/telleteditorial $>$ [Accessed 10 April 2021].

Bhowmik, M., 2015. Constructivism approach in mathematics teaching and assessment of mathematical understanding. Basic Research Journal of Education Research and Review, 4(1), pp. 8-12. 
Booth, G., 2010. The effects of homework assessment on student motivation and achievement. [pdf] Available at: $<$ https://pdfs.semanticscholar.org/2876/38f3e2c772636337488c62f337fd0fb6fb60.pdf> [Accessed 26 August 2017].

Carnegie Mellon University, n.d. Student lack of interest or motivation. [online]. Available at: $<$ https://www.cmu.edu/teaching/solveproblem/strat-lackmotivation/lackmotivation-02.html $>$ [Accessed 20 August 2017]

Crisp, G., Guàrdia, L. and Hillier, M., 2016. Using e-Assessment to enhance student learning and evidence learning outcomes. International Journal Educational Technology in Higher Education, [e-journal] 13(18). https://doi.org/10.1186/s41239-016-0020-3.

Denzine, G. and Brown, R., 2015. Motivation to learn and achievement. In: R. Papa (ed) Media rich instruction. Cham: Springer. https://doi.org/10.1007/978-3-319-00152-4 2.

Durham Public Schools (DPS), n.d. Characteristics of 21st Century Learners. [online] Available at: < https://sites.google.com/a/dpsnc.net/dps-literacy-framework/21st-century-literacy/characteristics-of-21st-centurylearners $>$ [Accessed 10 April 2021].

Fared, J., Jdaitawi, M., and Sheta, H., 2018. Fostering positive adjustment behavior: Social connectedness, achievement motivation and emotional-social learning among male and female university students. Active Learning in Higher Education, [e-journal] 19 (2), 145-158. doi.10.1177/1469787417731202.

Fernández-Martín, F., Romero-Rodríguez, J., Gómez-García, G. and Navas-Parejo, M., 2020. Impact of the flipped classroom method in the mathematical area: a systematic review. [online]. http://dx.doi.org/10.3390/math8122162.

Guàrdia, L., Crisp, G., and Alsina, I., 2017. Trends and challenges of e-assessment to enhance student learning in higher education. Innovative Practices for Higher Education Assessment and Measurement, [e-journal] (pp. 36-56). Abstract only. Available through: Semantic Scholar website < tps://www.semanticscholar.org/paper/Trends-and-Challengesof-E-Assessment-to-Enhance-in-Guàrdia-Crisp/bcf946fb3df8c405b17033230b6ccb12f2264506> [Accessed 10 April 2021].

International Bureau of Education (IBE), n.d. Technology-enhanced learning. [online] Available at: $<$ http://www.ibe.unesco.org/en/glossary-curriculum-terminology/t/technology-enhanced-learning $>$ [Accessed 10 April 2021].

James, R., 2016. Tertiary student attitudes to invigilated, online summative examinations. International Journal of Educational Technology Higher Education, [e-journal] 13(19). https://doi.org/10.1186/s41239-016-0015-0.

Jdaitawi, M., 2020. Does flipped learning promote positive emotions in science education? A comparison between traditional and flipped classroom approaches. Electronic Journal of e-learning, [e-journal]. 18(6), pp. 516-524. doi: 10.34190/JEL.18.6.004

Jeong, J., Canada, F., and Gomez, D., 2018. The study of flipped classroom for pre-service Science teachers. Education Science, [e-journal] 8(163). doi:10.3390/educsci8040163.

Joaquin, J., Biana, $\mathrm{H}$, and Dacela, M., 2020. The Philippine higher education sector in the time of COVID-19. [online] Available at: < https://www.frontiersin.org/articles/10.3389/feduc.2020.576371/full> Accessed [15 September 2021].

Kalogiannakis, M., and Papadakis, S., 2019. Evaluating pre-service kindergarten teachers' intention to adopt and use tablets into teaching practice for natural sciences. International Journal of Mobile Learning and Organisation. 13. doi: 10.1504/IJMLO.2019.096479

Korkmaz, O. and Karakus, U., 2009. The impact of blended learning model on student attitudes towards geography course and their critical thinking dispositions and levels. The Turkish Online Journal of Educational Technology, 8(4), pp. 5163.

Laine, K., Sipilä, E., Anderson, M., and Sydänheimo, L., 2016. Electronic exam in electronics studies. Paper presented at the SEFI Annual Conference 2016: Engineering Education on Top of the World: Industry University Cooperation. Tampere, Finland. Available at: http://sefibenvwh.cluster023.hosting.ovh.net/wp-content/uploads/2017/09/laine-electronicexam-in-eletronics-studies-9.pdf [Accessed 11 September 2021]

Moreno-Guerrero, A., Aznar-Diaz, I., Caceres-Reche, P. and Alonoso-Garcia, S., 2020. E-learning in the teaching of mathematics: an educational experience in adult high school. Mathematics 2020. doi:10.3390/math8050840

Papadakis, S. 2018. Evaluating pre-service teachers' acceptance of mobile devices with regards to their age and gender: A case study in Greece. International Journal of Mobile Learning and Organisation. 12. doi: 10.1504/IJMLO.2018.095130

Papadakis, S., Kalogiannakis, M., Sifaki, E. and Vidakis, N., 2018. Access Moodle using smart mobile phones. a case study in a Greek university. In: A. Brooks, E. Brooks and N. Vidakis (eds) Interactivity, Game Creation, Design, Learning, and Innovation. ArtsIT 2017, DLI 2017. Lecture Notes of the Institute for Computer Sciences, Social Informatics and Telecommunications Engineering, vol 229. pp. 376-385. [online] http://dx.doi.org/10.1007/978-3-319-76908-0 36

Proprofs Training Maker, n.d. What is an LMS? [online]. Available at: <https://www.proprofs.com/training/Ims-software/ $>$ [Accessed 21 August 2017]

Rosario, P., Nunez, Vallejo, G., Cunha, J., Nunes, T., Mourao, R and Pinto, R., 2015. Does homework design matter? the role of homework purposes on students' mathematics achievement. Contemporary Educational Psychology, [e-journal] 43, pp. 10-24. doi: 10.1016/j.cedpsych.2015.08.001

Sarmiento, C., 2017. Student perceptions of online homework in mathematics of accounting and finance. Advanced Science Letters, 23, pp. 1122-1125. 
Sarmiento, C., Lapinid, M., and Prudente, M., 2018. The effect of online homework in the performance of mathematics of accounting and finance students. Advanced Science Letters, 24(11). 7956-7960. DOI:10.1166/asl.2018.12465

Ssekakubo, G., Suleman, H. and Marsden, G., 2013. Designing mobile LMS interfaces: learners' expectations and experiences. Interactive Technology and Smart Education, 10(2), pp. 147-167 [online] Available at: $<$ https://core.ac.uk/download/pdf/232196429.pdf> [Accessed 17 April 2021].

Tang, G. and Titus, A., 2002. Increasing students' time on task in calculus and general physics courses through WebAssign. Proceedings of the 2002 American Society for Engineering Education Annual Conference \& Exposition. [pdf] Available at: $<$ https://www.semanticscholar.org/paper/Increasing-Students'-Time-on-Task-in-Calculus-and-TangTitus/ef9f1de1babd7124eed0c651560424087ca29de8> [Accessed 26 August 2017].

Tuan, H., Chin, C. and Shieh, S., 2005. The development of a questionnaire to measure students' motivation towards science learning. International Journal of Science Education, 27(6), pp. 639-654.

University at Buffalo, 2019. Strongly agree: the number of response options matter when using a Likert scale: psychologist's research suggest that a response format should be given as much thought as the test itself [online] Available at $<$ www.sciencedaily.com/releases/2019/04/190423114033.htm > [Accessed 28 May 2020].

Wanner, T. and Palmer, E., 2015. Personalising learning: Exploring student and teacher perceptions about flexible learning and assessment in a flipped university course. Computers \& Education. 88, 354-369. https://doi.org/10.1016/i.compedu.2015.07.008.

Zerr, R. 2007. A quantitative and qualitative analysis of the effectiveness of online homework in first-semester calculus. Journal of Computers in Mathematics and Science Teaching, 26(1), pp.55-73. 